\title{
MODELING OF A TURBOCHARGER WITH THE DIESEL ENGINE AND CONTROL OF COMPRESSOR SURGE
}

\section{Ahmed Sayed Hassan}

Mechanical Engineering Department, Assiut, University, Assiut, Egypt.

(Received Dec.11, 2006, Accepted January 20, 2007 )

The main target for the present work is to study how to prevent the turbocharged diesel engine from the very dangerous problem of compressor surge. Different controllers to broaden the region of stable operation of the compressor, and thus, improve diesel engine performance were investigated. In the first, a simple model for the turbocharger with the diesel engine is created out. This model includes nine states, which represents the different subsystem components: air filter, intake manifold, intercooler, exhaust manifold, exhaust system, exhaust gas recirculation, compressor and turbine. Effects of each system components on the engine performance have been investigated. The second part, investigates the compressor surge phenomenon, its dangerous on the diesel engine stability and range of stable flow operation. Also, different techniques to suppress or for controlling the surge phenomenon and increase of the range of stable operation of the compressor were carried out. These techniques are the changes of engine intake manifold volume, throttle gain, auxiliary plenum, closed coupled valve and bleed valves. Comparisons of the present theoretical results with the available previous experimental and theoretical results were carried out.

The results show that the required power for the compressor was increased by increasing the losses through the air filter and the intake manifold. The engine volumetric efficiency and the output power are increased by increasing the intake manifold pressure. With increasing the residual gas fraction, both the exhaust manifold temperature and the engine output power decrease. Decreasing the volume of the engine intake manifold increases the engine stability. The throttle valve with new gain as a controller improved the compressor range of stable operation by about $33 \%$ and about $15.4 \%$ improvement in pressure coefficient at low flow rate. Use the closed-coupled control valve as a controller for compressor surge gives an enhancement in compressor stable flow range of about $25 \%$, and $10.8 \%$ in pressure coefficient. While, the auxiliary plenum and the bleed valves give improvement in surge point about $20 \%$ 
and $16 \%$ respectively. The present work shows good agreement in comparison of available experimental data from the previous investigations.

KEYWORDS: Turbocharger, Compressor, Turbine, Modeling, Diesel Engine.

\begin{tabular}{|c|c|c|c|}
\hline \multicolumn{4}{|c|}{ NOMENCLATURE } \\
\hline $\mathrm{A}$ & area, $\mathrm{m}^{2}$ & $\gamma$ & specific heat ratio, $\mathrm{Cp} / \mathrm{Cv}$ \\
\hline$A / F$ & $F$ Air-to-fuel ratio & $\eta$ & efficiency, \% \\
\hline & speed of sound, $\mathrm{m} / \mathrm{s}$ & $\rho$ & density, $\mathrm{kg} / \mathrm{m}^{3}$ \\
\hline B & $\begin{array}{l}\text { stabillity parameter }= \\
(u / 2 a) \sqrt{V_{p} / A_{c} L_{c}}\end{array}$ & $\Phi$ & $\begin{array}{l}\text { flow coefficient }=\dot{m} / \rho A u \\
=C x / u\end{array}$ \\
\hline$C$ & slope & $\Psi$ & pressure coefficient \\
\hline $\mathrm{Cp}, \mathrm{C}$ & Cv specific heats, $\mathrm{kJ} / \mathrm{kgK}$ & & $=2 \Delta P / \rho \mathrm{u}^{2}$ \\
\hline$C_{x}$ & axial velocity, $\mathrm{m} / \mathrm{s}$ & $\tau$ & nondimensional time \\
\hline EGR & exhaust gas recirculation & Subsc & ripts \\
\hline$H$ & pressure ratio at zero flow rate & $\mathrm{a}$ & air, ambient \\
\hline$h$ & specific enthalpy, kJ/kg & & air filter \\
\hline$I$ & polar moment of inertia, $\mathrm{m}^{4}$ & & compressor \\
\hline$L_{c}$ & effective compressor duct length, & & close coupled \\
\hline $\begin{array}{c}\mathrm{m} \\
\dot{m}\end{array}$ & mass flow rate, $\mathrm{kg} / \mathrm{s}$ & $\begin{array}{l}\mathrm{cm} \\
\mathrm{cyl}\end{array}$ & $\begin{array}{l}\text { cooling medium of intercooler } \\
\text { cylinders }\end{array}$ \\
\hline $\mathrm{N}$ & speed, m & $\mathrm{e}$ & exit \\
\hline $\mathrm{P}$ & power, watts & en & engine \\
\hline $\mathrm{p}$ & pressure, $\mathrm{Pa}$ & exm & exhaust manifold \\
\hline$\Delta p$ & pressure difference, $\mathrm{Pa}$ & exs & exhaust system \\
\hline$\Pi$ & pressure ratio & $\mathrm{f}$ & fuel \\
\hline$Q$ & volume flow rate, $\mathrm{m}^{3} / \mathrm{s}$ & HV & heating value \\
\hline$q$ & specific energy per unit mass, & & intercooler \\
\hline & $\mathrm{kJ} / \mathrm{kg}$ & im & intake manifold \\
\hline$r$ & rotor radius, $\mathrm{m}$ & o & outlet condition \\
\hline $\mathrm{T}$ & temperature, $\mathrm{K}$ & $\mathrm{p}$ & plenum \\
\hline $\mathrm{t}$ & time, $\mathrm{s}$ & $r$ & recirculation (EGR) \\
\hline $\mathrm{u}$ & rotor tangent speed, $\mathrm{m} / \mathrm{s}$ & $\mathrm{T}$ & throttle \\
\hline$\Gamma$ & nondimensional torque & $\mathrm{t}$ & turbine \\
\hline
\end{tabular}

\section{1- INTRODUCTION}

In the present days, almost all modern diesel engines cars are equipped with the turbochargers due to the significance of the turbochargers improvement of the engines 
performance [1, 2], the driveability and the emissions [3]. However, in the turbocharged engine, the energy in the exhaust gases drives the turbine, which is connected to a compressor through the turbine shaft and hence the pumping capacity of the compressor depends on the amount of energy that the turbine can transmit from the exhaust gases. Therefore, specification of a turbocharger for a given engine involves matching the turbocharger performance characteristics with those of the piston engine [4-9]. Kristoffersson [10] concluded that using the turbocharger reduces the size of the engine without loss for torque produced and hence better fuel consumption. In addition, modern diesel engines are typically equipped with variable geometry turbochargers $[7,8,11,12]$ and exhaust gas recirculation $[1,2,9,12,13-25]$. On the other hand, it is well known that, operating the engine in presence of compressor surge may stop the flow through or inside the cylinders that lead to loss of some engine power or engine knocks [26-36]. In the present work, with the aim to prevent the turbocharged diesel engine from the compressor surge, a simple model for the turbocharger with the diesel engine was introduced and different methods for control of the compressor surge were investigated.

The present model investigate effect of each of the system elements on the engine performance: air filter, intake manifold, intercooler, exhaust manifold, exhaust system, exhaust gas recirculation, compressor and turbine. Different techniques to suppress or control of the compressor surge phenomenon and to increase the range of stable operation were investigated. These techniques are the changes of engine intake manifold volume, throttle gain, auxiliary plenum, closed coupled valve and bleed valves. Comparisons of the present results with the available previous experimental and theoretical results were carried out to examine the validity of the obtained results.

\section{MODELING OF TURBOCHARGER WITH THE DIESEL ENGINE}

Figure 1 shows a turbocharger with diesel engine model, which includes also the air filter, intake manifold, intercooler, exhaust manifold, exhaust system, exhaust gas recirculation, turbocharger, compressor and turbine. The intake air through the air filter is compressed in the compressor, cooled in an intercooler and then the throttle valve can decide how much air is blown into the engine. The exhaust gases flow out through the exhaust manifold and, if the waste gate is closed, it goes to the turbine, which starts to rotate due to the energy in the exhaust gases. Then, the exhaust gases flow through an exhaust system (catalyst) and out to the atmosphere. The exhaust gas recirculation valve controls the second path from the exhaust manifold to the engine intake causing exhaust gas recirculation (EGR). 


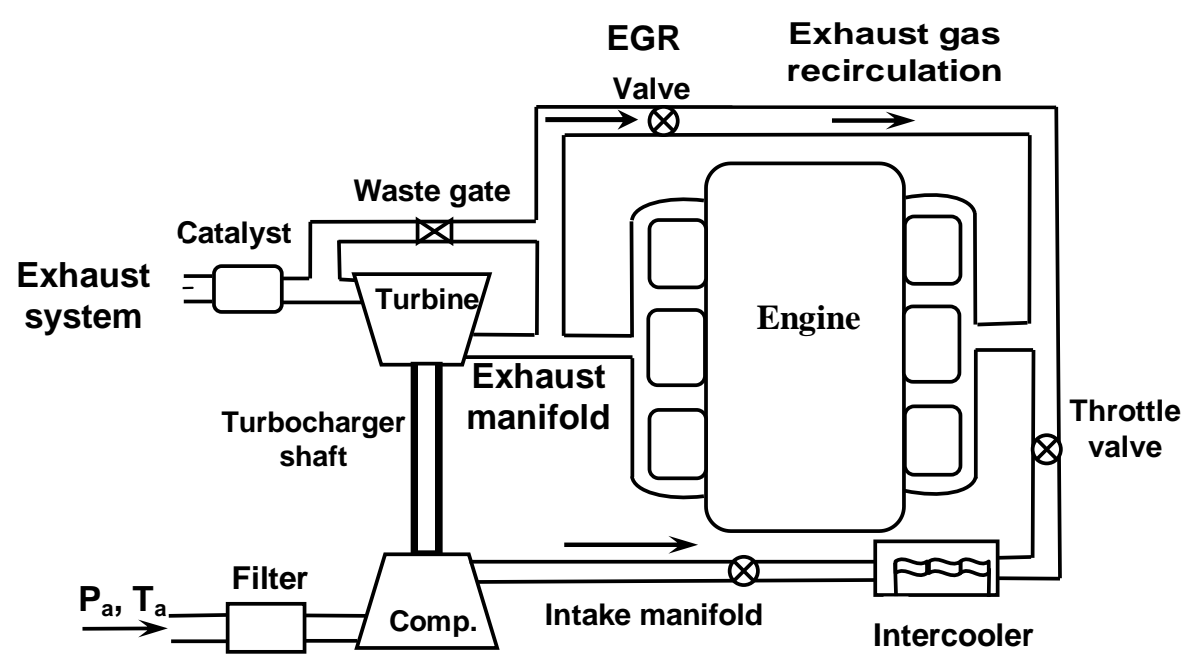

Fig. 1: Model of the turbocharger with the diesel engine

\subsection{Effect of Pressure Loss through the Air Filter and Intercooler on the Engine Performance}

The pressure loss through the air filter is modeled as a tube filled with a porous medium, which can be written as:

$$
p_{L, a f}=p_{a}-p_{a f}=k_{1}\left(\dot{m}_{a} R T_{a} / p_{a}\right)+k_{2}\left(\dot{m}_{a} R T_{a} / p_{a}\right)^{2}
$$

Also, the pressure losses through the intercooler is modeled similar to [3] as follows:

$$
p_{L, i c}=k_{3} T_{c} \dot{m}_{a}^{2} / p_{c}
$$

where, $k_{1}, k_{2}$ and $k_{3}$ are constants.

The total pressure loss through the air filter and intercooler using Eqs (1 and 2) is:

$$
p_{L, a f, i c}=k_{1}\left(\dot{m}_{a} R T_{a} / p_{a}\right)+k_{2}\left(\dot{m}_{a} R T_{a} / p_{a}\right)^{2}+k_{3} T_{c} \dot{m}_{a}^{2} / p_{c}
$$

Equation (3) shows that the losses through the air filter and intercooler are increase with increasing the compressor mass flow rate. Therefore, the power required to drive the compressor increases by increasing these pressure losses. In addition, these pressure losses are function of the ambient pressure and temperature. This means that the whole engine performance could be influenced by the ambient conditions.

\subsection{Effect of the Intake and Exhaust Manifolds on Engine Performance}

The change of the pressure in the intake and exhaust manifolds using an ideal gas law in differentiating form and assuming the variations in temperature is very small, $\dot{T}=0$, can be written as:

$$
\dot{p}_{i m} V_{i m}=R T_{i m}\left(\dot{m}_{i m, i}-\dot{m}_{i m, o}\right)
$$




$$
\dot{p}_{e m} V_{e m}=R T_{e m}\left(\dot{m}_{e m, i}-\dot{m}_{e m, e}\right)
$$

Assuming the mass flow into the intake manifold equals the mass flow trough the compressor, $\left(\dot{m}_{i m, i}=\dot{m}_{c}\right)$ and the mass flow out of the intake manifold equals to the mass flow into the engine $\left(\dot{m}_{i m, o}=\dot{m}_{e n}\right)$. The engine intake mass flow is:

$$
\dot{m}_{e n}=\eta_{v o l}\left[\left(\dot{p}_{i m} V_{d} N_{c y l} n_{e n}\right) /\left(60 N_{r} R T_{i m}\right)\right]
$$

where, $\eta_{v o l}$ is the engine volumetric efficiency, $V_{d}$ is the displacement volume, $N_{c y l}$ is the number of cylinders, $n_{e n}$ is the engine speed (rev./min), $N_{r}$ is the number of revolutions per cycle, $R$ is the gas constant and $T_{i m}$ is the intake manifold temperature. Equation (6) shows the engine volumetric efficiency $\eta_{v o l}$, increasing with increasing the intake manifold pressure. That is the engine output increases with using the turbocharger, which increases the engine intake pressure.

Whereas, the pressure losses through the intake and exhaust manifolds are assumed as:

$$
\begin{aligned}
& p_{L, i m}=k_{4} T_{c, e} \dot{m}_{a}^{2} / p_{c, e} \\
& p_{L, e m}=k_{5} T_{e m} \dot{m}_{e m}^{2} / p_{e m}
\end{aligned}
$$

On the other hand, if it is assumed that, the exhaust gas recirculation (EGR) valve and the waste gate are closed, then the mass flow out of the exhaust manifold is assumed to be the same as the mass flow through the turbine $\dot{m}_{e m, e}=\dot{m}_{t}$. Also, the mass flow out of the engine (which equals the sum of the mass flow into the cylinders and the mass flow of injected fuel, $\dot{m}_{e n, e}=\dot{m}_{e n, i}+\dot{m}_{f}$ is the mass flow into the exhaust manifold $\dot{m}_{\text {emi }}=\dot{m}_{\text {ene }}$. The exhaust manifold inlet mass flow is equal its outlet, $\dot{m}_{e m, i}=\dot{m}_{e m, e}$. However, for an ideal Otto cycle, the exhaust manifold temperature can be written as:

$$
T_{e m}=T_{a}\left(p_{e m} / p_{i m}\right)^{(\gamma-1) / \gamma_{[1}}\left[q_{i n} /\left(c_{v} T_{a} \Pi_{c}^{\gamma-1}\right)\right]^{1 / \gamma}
$$

And the specific energy content of the charge per mass flow can be written as:

$$
q_{i n}=\left(1-x_{r}\right) \dot{m}_{f} q_{H V} /\left(\dot{m}_{i m}+\dot{m}_{f}\right)
$$

The residual gas fraction $x_{r}$ can be written similar to [17] as:

$$
x_{r}=\left\{\left(p_{\text {em }} / p_{\text {im }}\right)^{1 / \gamma}\left[1+q_{\text {in }} /\left(c_{v} T_{a} \Pi_{c} \gamma^{e-1}\right)\right]^{-1 / \gamma}\right\} / \Pi_{c}
$$

Substituting Eq.(10) into Eq.(9) and solving Eqs.(8 and 9) using the Matlab gives the exhaust manifold temperature as a function of residual gas fraction and the results are represents in Fig.2. The figure shows that increasing in the residual gas fraction decreases the exhaust manifold temperature. 




Fig.2 Effect of residual gas fraction on exhaust manifold temperature

\subsection{Turbocharger Description Modeling}

Usually, the air required by the diesel engine determines the basic size of the turbocharger $\left(\dot{m}_{a}=\eta_{v} \rho_{a} V_{d} N / n\right)$. If the engine is run at constant speed but increasing load, the mass-flow rate will increase almost proportionately with the increasing charge density or pressure ratio of the compressor. The appropriate turbocharger could be chosen from compressor characteristic maps (obtained from steady-flow tests) which provided by turbocharger manufacturers, and comparing that with the fuel map of the engine. The turbocharger compressor maps are used to identify minimum airflow, limit for continuous operation and minimum compressor efficiency. Therefore, determination of the compressor characteristic map correctly, explaining the steady and unsteady operation (range of stable operation) will avoid the diesel engine from unsteady compressor operation or surge phenomenon. The conservation of energy (stored energy per time $=$ produced power - consumed power) can be written as:

$$
d E / d t=I \dot{\omega} \omega=P_{t}-P_{c, \text { total }}=\omega\left(M_{t}-M_{c}\right)
$$

where $E$ is the energy stored in the rotating parts of the turbocharger, $P_{t}$ and $P_{c, t o t a l}$ are the power produced by the turbine and the total power consumed by the compressor respectively, $I$ is the moment of inertia of the turbocharger, $M_{t}$ is the driving torque, $M_{c}$ denotes braking torque acting on the rotating parts of the turbocharger spinning with the angular velocity $\omega$.

\subsubsection{Compressor Performance Characteristics}

The target at this part from the present research, which is very important for protection of the turbocharged diesel engine from the very dangerous surge problem, is to determine the compressor surge limit or range of stable operation. Doing this requires drawing for the compressor performance characteristic and defines the steady and unsteady operations as well as the surge phenomenon. The second step is how to 
increase the range of stable operation for the compressor, by making suppression for the surge problem or to control of surge, which will increase the range of stable operation. First of all, the compressor characteristic map must be defined, the stable region and surge line as well as maximum efficiency points for different speed lines must be clearly shown. The region, which just before surge line must be also defined. However, the compressor power can be evaluated using the first law of thermodynamics for an adiabatic process of an ideal gas with constant specific heats as:

$$
P_{c}=\dot{m}_{a} c_{p}\left(T_{c}-T_{a}\right)=\dot{m}_{a} c_{p} T_{a}\left[\left(\Pi_{c}\right)^{(\gamma-1) / \gamma}-1\right] / \eta_{c}
$$

Where the compressor pressure ratio as a function of mass flow rate can be written as:

$$
\Pi_{c}=\left\{1+u_{c}^{2}\left[a_{1}\left(\dot{m}_{a} / u_{c}\right)^{2}+a_{2}\left(\dot{m}_{a} / u_{c}\right)+a_{3}\right] / c_{p} T_{a}\right\}^{\gamma /(\gamma-1)}
$$

where, $u_{c}$ is the rotor tip speed and $a_{i}$ are tuning constants.

That is the total power required to drive the compressor, using Eqs.(3, 7 and 12) is:

$$
\begin{aligned}
P_{c, \text { total }}= & \dot{m}_{a} c_{p} T_{a}\left(\Pi_{c}^{(\gamma-1) / \gamma}-1\right) / \eta_{c}+k_{1}\left(\dot{m}_{a} R T_{a} / p_{a}\right) \\
& +k_{2}\left(\dot{m}_{a} R T_{a} / p_{a}\right)^{2}+k_{3} T_{c} \dot{m}_{a}^{2} / p_{c}+k_{4} T_{c, e} \dot{m}_{a}^{2} / p_{c, e}
\end{aligned}
$$

\subsubsection{Turbine Performance Characteristics}

The net amount of produced turbine power can be written as:

$$
P_{t}=\dot{m}_{t} c_{p} T_{e m} \eta_{t}\left[1-\left(p_{t} / p_{e m}\right)^{(1-\gamma) / \gamma}\right]
$$

In addition, the turbine efficiency can be written as:

$$
\eta_{t}=\left(1-T_{t} / T_{e m}\right) /\left[1-\left(T_{t} / T_{e m}\right)^{(\gamma-1) / \gamma}\right]
$$

Equations. (15and16) show the turbine power and efficiency are connection between the flow and pressure ratio and independent of the compressor speed. To make the model more general, the volume flow should be considered instead of mass flow as explained in earlier sections. The instantaneous turbine torque can be written as:

$$
M_{t}=30 \dot{m}_{t} c_{p} \eta_{t}\left(1-\Pi_{t}^{(\gamma-1) / \gamma}\right) / \pi N
$$

However, inserting (17), (14) into (11), yields the final expression for the turbine shaft speed model. Figure 3 shows the compressor characteristic including the range of stable operation, turbine pressure ratio and the turbocharger net power. The figure shows that the turbocharger operation is limited due to compressor surge as well as choke. That is the diesel engine must be operated at air mass flow rate higher than $0.27 \mathrm{~kg} / \mathrm{s}$ and if it works at flow rate less than this valve it will inter in unsteady operation due to compressor surge. This figure emphasized that turbocharged diesel engine stabilization is dependent on the range of stable operation of the compressor. 


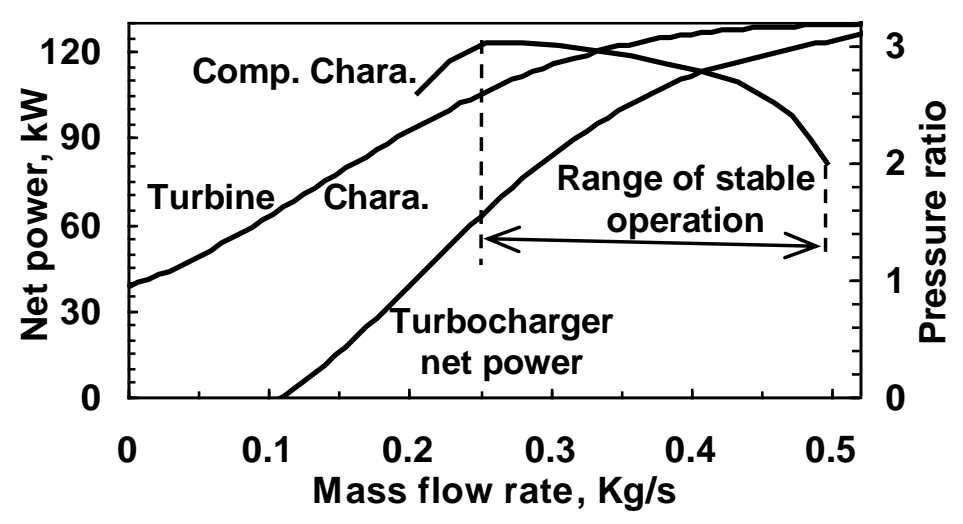

Fig. 3 Effect of compressor range of stable operation on diesel engine stability

\subsection{Exhaust Gas Recirculation for Diesel Engine with Turbocharger}

The recirculation of exhaust gas from the upstream of the turbocharger turbine through an EGR valve into the intake manifold where it dilutes the incoming fresh air is denoted as EGR system. The EGR is one of the most effective methods for reducing the emissions of nitrogen oxides (NOx) of diesel engines [31]. However, to study the effect of EGR on the engine performance, a simple model similar to that used for the intake manifold dynamics is described by differentiating the ideal gas law, $p V=m R T$ resulting in a differential equation (assume $\dot{T}=0$ )can be written as:

$$
\dot{p}_{i m}=R T_{i m}\left(\dot{m}_{E G R}+\dot{m}_{c}-\dot{m}_{e n}\right) / V_{i m}
$$

where, $V_{i m}$ is the intake manifold volume. Assuming no mass is accumulated in the EGR system, if the exhaust manifold pressure and temperature are known, the flow through the EGR valve can be determined by using standard orifice flow equation [17]:

$$
\dot{m}_{E G R}=A_{r} p_{e m}\left(R T_{e m}\right)^{-0.5}\left[\left(2 p_{\text {im }} / \frac{p_{\text {im }}}{p_{\text {em }}}\right)\left(1-\frac{p_{\text {im }}}{p_{\text {em }}}\right)\right]^{0.5}
$$

where $A_{r}$ is the effective area of the EGR valve. Substituting Eqs.(6) into Eq. (18) the compressor mass flow rate can be written as:

$$
\dot{m}_{c}=\dot{m}_{a}=\frac{V_{\text {im }}}{R T_{\text {im }}} \dot{p}_{i m}-\frac{A_{r} p_{\text {em }}}{\sqrt{R T_{\text {em }}}} \sqrt{2 \frac{p_{\text {im }}}{p_{\text {em }}}\left(1-\frac{p_{\text {im }}}{p_{\text {em }}}\right)}+\eta_{\text {vol }} \frac{\dot{p}_{\text {im }} V_{d} N_{c y l} n_{\text {en }}}{60 N_{r} R T_{i m}}
$$

Equation 20 shows that in case of the turbocharged diesel engine, the compressor mass flow rate is very important for engine stability to avoid the surge problems. On the other hand, this equation shows also that increasing the EGR decreases the compressor mass flow rate. Therefore, the outlet pressure ratios from the compressor and in parallel the outlet temperature from the compressor are decreased. That is the exhaust gas temperature decreases with using exhaust gas recirculation 
with the diesel engine. This leads to decrease in the NOx emission in the diesel engine because, the specific heat of the EGR is much higher than fresh air, hence EGR increases the heat capacity of the intake charge, thus decreasing the temperature rise for the same heat release in the combustion chamber.

\section{COMPRESSOR SURGING WITH DIESEL ENGINE TRANSIENT OPERATION}

It is well known that, the compressor is more sensitive for variations in mass flow and pressure ratios than the turbine and most stability problems of the turbocharger are due to the compressor surge, which occurs when the mass flow rate is low. Whereas, the engine runs mostly at quite low loads during normal driving where the mass flow into the cylinders is low and consequently the compressor is run at low flow rate. Therefore, the diesel engine with a turbocharger needs a wide range of stable flow operation to avoid the problems of surge. For this reason, the transient operation of the diesel engine load has effect on the compressor surge and hence the engine stability will be discussed in the following sections.

\subsection{Governing Equations and Compressor characteristic}

The surge margin is usually adequate under steady state conditions, when the diesel engine operates under dynamic conditions, in which the turbocharger compressor may be driven beyond its surge limit [22-24]. To detect the compressor stable and unstable operations and hence range of stable operation, a compression system such as shown in Fig. 4 is represented. This system consists of a centrifugal compressor, an intake plenum located downstream the compressor and a valve connected between the plenum and the engine intake. The compressor is part of the engine turbocharger and is connected to the turbocharger turbine across a common shaft. The conservation of momentum in the compressor exit duct can be written as:

$$
L_{c} d\left(\rho_{c} C_{x}\right) / d t=P_{a}-P_{p}+\Delta P_{c}
$$

Conservation of mass in the plenum is given by:

$$
d\left(\rho_{P} V_{P}\right) / d t=\dot{m}_{c}-\dot{m}_{T}
$$

Conservation of angular momentum in the turbocharger shaft (Eq.11) is given by:

$$
I d \omega / d t=I \dot{\omega}=M_{t}-M_{c}
$$

Equations (21) and (22) can be written in nondimensional form as follows:

$$
\begin{aligned}
& d\left(B \Phi_{c}\right) / d \tau=B^{2}\left[\Psi_{c}\left(\Phi_{c}\right)-\Psi_{p}\right] \\
& d\left(B^{2} \Psi_{p}\right) / d \tau=B^{2}\left(\Phi_{c}-\Phi_{T}\right)
\end{aligned}
$$

If the torque $M$ is nondimensionalized by $\rho A_{c} r u^{2}$, Eq.(23) becomes:

$$
d B / d \tau=F B^{2} \Gamma
$$


where, $\quad F=2 \rho L_{c} A_{c} r^{2} / I, \quad \Gamma$ is the nondimensional net torque, $\Gamma=\Gamma_{t}-\Gamma_{c}$. Substituting Eq.(26) into Eqs.(24) and (25) gives:

$$
\begin{aligned}
& d \Phi_{c} / d \tau=B\left[\Psi_{c}\left(\Phi_{c}\right)-\Psi_{p}\right]-F B \Phi_{c} \Gamma \\
& d \Psi_{p} / d \tau=\left(\Phi_{c}-\Phi_{T}\right)-2 F B \Psi_{p} \Gamma
\end{aligned}
$$

The compressor characteristics in the region beyond the surge line can be estimated similar to [28] by using the following equation:

$$
\Pi_{c}=H+\beta\left\{1+1.5\left[\left(\dot{m}_{c} / \varphi\right)-1\right]-0.5\left[\left(\dot{m}_{c} / \varphi\right)-1\right]^{2}\right\}
$$

where, $H$ is the pressure ratio at zero flow, $\beta, \varphi$ are parameters that shown in Fig.5.

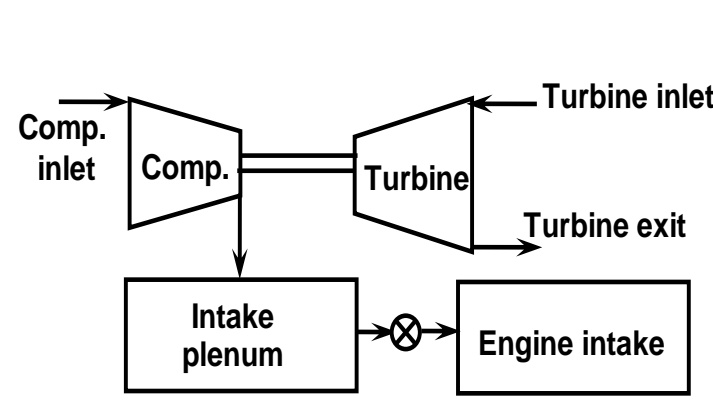

Fig. 4 Compression system

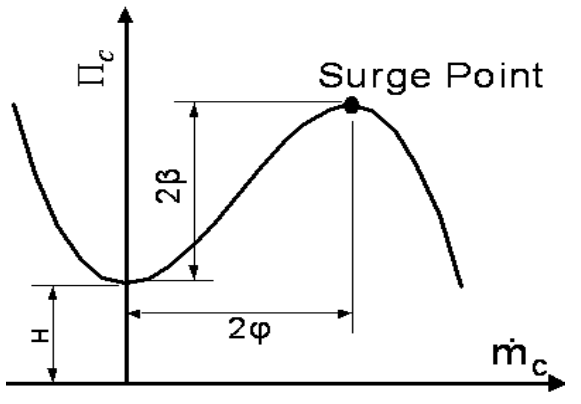

Fig.5 Compressor characteristic

The complete compressor performance characteristic or pressure coefficient as a function of flow coefficient $\Psi_{p}(\Phi)$ can be written as [27]:

$$
\Psi_{p}=0.23 \arctan (20(\Phi-0.22))+1.38-5.6 \Phi+23.7 \Phi^{2}-49 \Phi^{3}
$$

Equations (26-28) are coupled set of nonlinear equations which were solved numerically using the Matlab for $B, \Phi_{c}$ and $\Psi_{p}$ with $\Psi_{p}\left(\Phi_{c}\right)$ and $\Gamma\left(\Phi_{c}\right)$ the specified compressor pressure coefficient (Eqs.29 and 30) and torque characteristic, respectively and the results are shown in Fig.6. The dynamic behavior of the compression system at $\Phi=0.23$ is shown in Fig.6a. The main compressor geometric data and the measured parameters are taken from [27], including the compressor flow coefficient $(\mathrm{Cx} / \mathrm{u})$, the impeller tip Mach number $\left(\mathrm{M}_{\mathrm{to}}\right)$, and the isentropic head coefficient ( $\Psi \mathrm{p})$, are shown in Fig.6b. The predicted results are agreement with the experimental data of [27]. This figure shows that when the compressor was operated at $\Phi=0.23$, Fig.6, the mass and pressure fluctuations are relatively small. While when the compressor was operated at flow coefficient of $\Phi=0.225$, the amplitude and shape of fluctuations are completely different due to occurring surge as shown in Fig.7. That is decreasing the compressor flow coefficient from $\Phi=0.3$ to 0.225 , leads to cause the compressor running in deep surge. However, when the compressor run at $\Phi=0.23$, Fig.6 shows initiation of unstable operation while when tested at $\Phi=0.225$ the results show deep surge operation. 


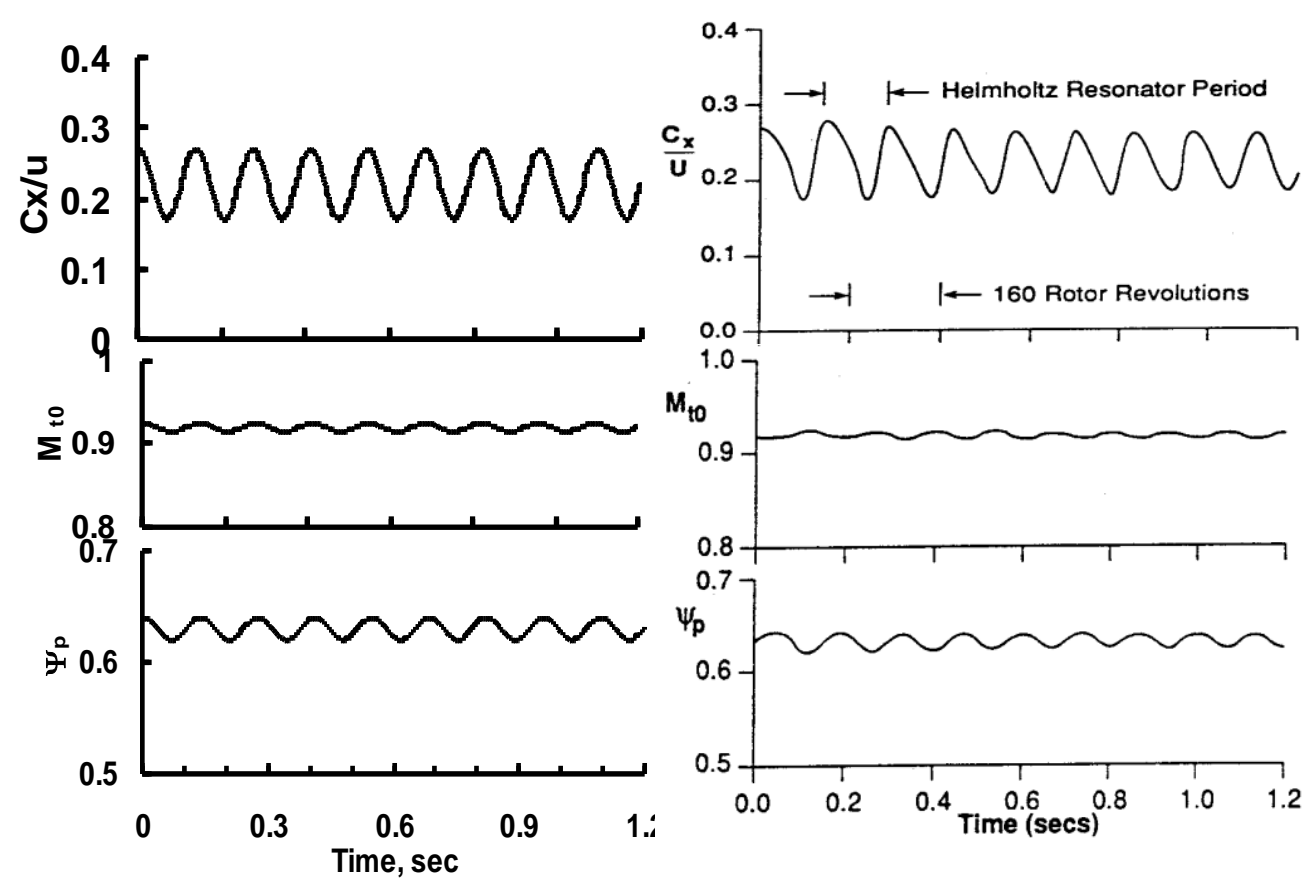

a-Present model

b-Experimental [27]

Fig.6: Present and measured [27] results for the system at $\Phi=0.23$

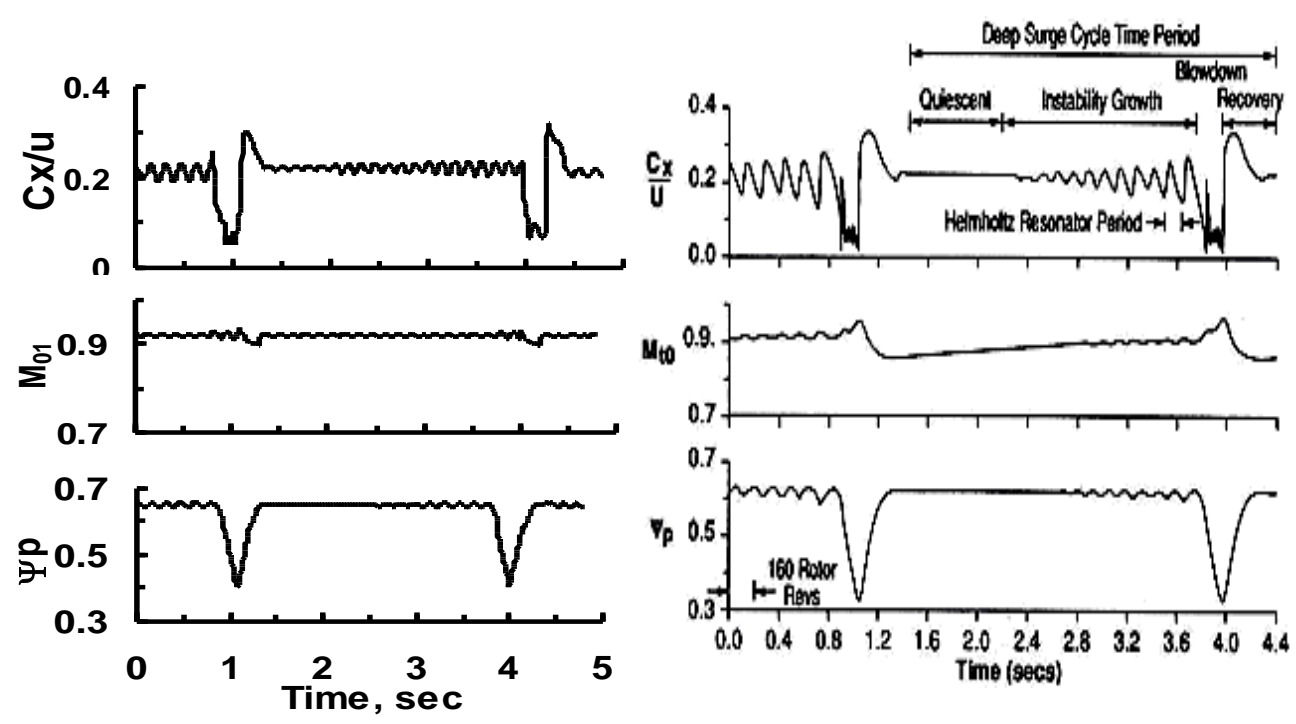

a-Present model

b-Experimental [27]

Fig. 7: Results of system without controller at $\Phi=0.225$ 
The changes in flow rate from $\Phi=0.23$ to $\Phi=0.225$ is very small but the compressor becomes unstable in deep surge. This indicated that the compressor is very sensitive for decreasing its mass flow rate even if the change in mass flow is very small. That is the engine may operate in dangerous operation due to operation of the compressor in surge condition. Therefore, and after detecting the compressor range of stable operation and the problems which can surge makes to the turbocharged diesel engine due to limited range of mass flow operation of the compressor, the next sections will try to extend the compressor range of stable operation or to suppressed the surge to avoid the turbocharged diesel engine from the unsteady operation.

\subsection{Effect of the Engine Intake Manifold on Compressor surge}

Fink et al. [27] concluded that, the volume of the compression system intake has the major effect on the form of the surge cycle. Therefore, this part of the present work investigates influence of the engine intake manifold volume on the compressor surge and engine performance. To show this effect, the volume of the engine intake manifold is decreased by $0.05 \mathrm{~m}^{3}$ or decreasing the parameter-B from 1.1 to 0.9. Applying this in Eqs. (26-28), the results with the experimental of [27] are shown in Fig.8. The figure shows the compressor becomes a little stable with the small volume of the plenum in respect of large plenum volume. The time is decreased or the number of cycles per sec is increased as shown in fig. 8 in comparison with those in Fig.7 even if the amplitudes of flow and pressure fluctuations are approximately the same. That is the compressor may run in mild surge instead of deep surge for the same flow coefficient, $\Phi=0.225$.

On the other hand, if the flow coefficient is mapped against pressure coefficient it will give so-called surge cycle as shown in Fig.9 to emphasize the above results for effect of engine intake manifold volume on the compressor surge. It is clear from the figure that the surge cycle diameter is decreased by decreasing the volume of intake manifold. With the small volume of the intake manifold the system was in mild surge, while at the same mass flow rate, the system is in deep surge at large volume of the intake manifold. In fact, many tests were carried out for decreasing volumes of the intake manifold or B-parameter and gave increases in range of stable operation depends on decreasing value of the parameter B. The results of these tests are not given in this paper because there are no available experimental data for the comparison. Figures (6-9) conclude that the compressor could enter in deep surge with very small changes in flow rate, which leads to stop of the flow from the compressor to the engine. That is the surge is very dangerous problem for the engine and must be controlled or suppressed to protect the engine from this phenomenon. Therefore, the next section tries to increase the compressor range of stable operation by controlling the compressor surge. 


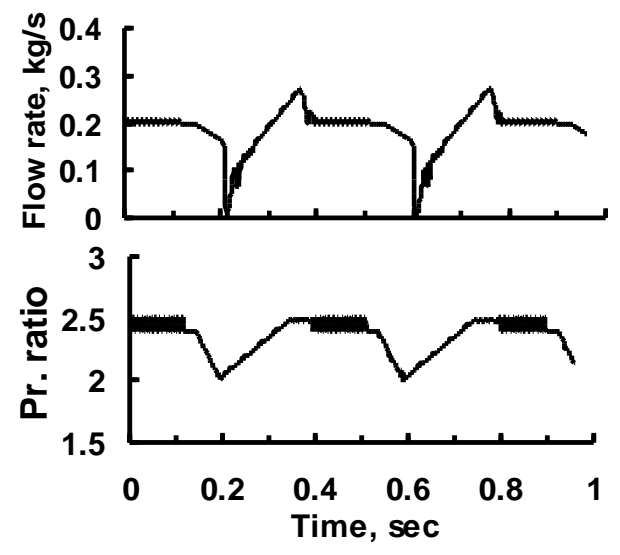

a-Present model

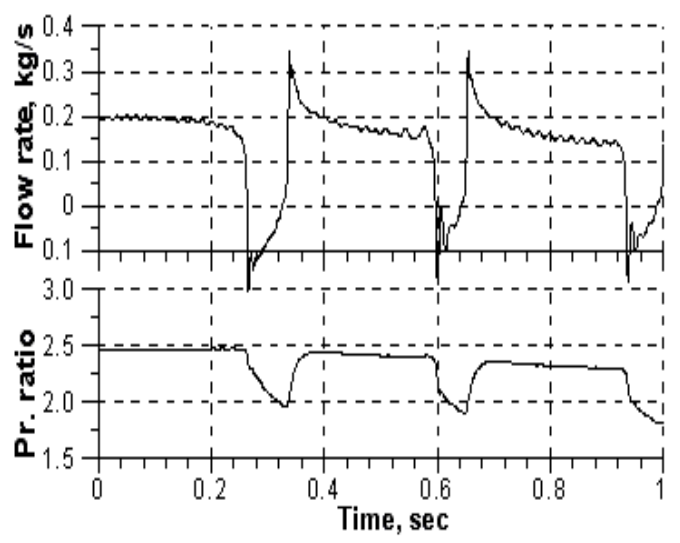

b-Experimental [27]

Fig. 8 Results at large volume of the engine intake manifold

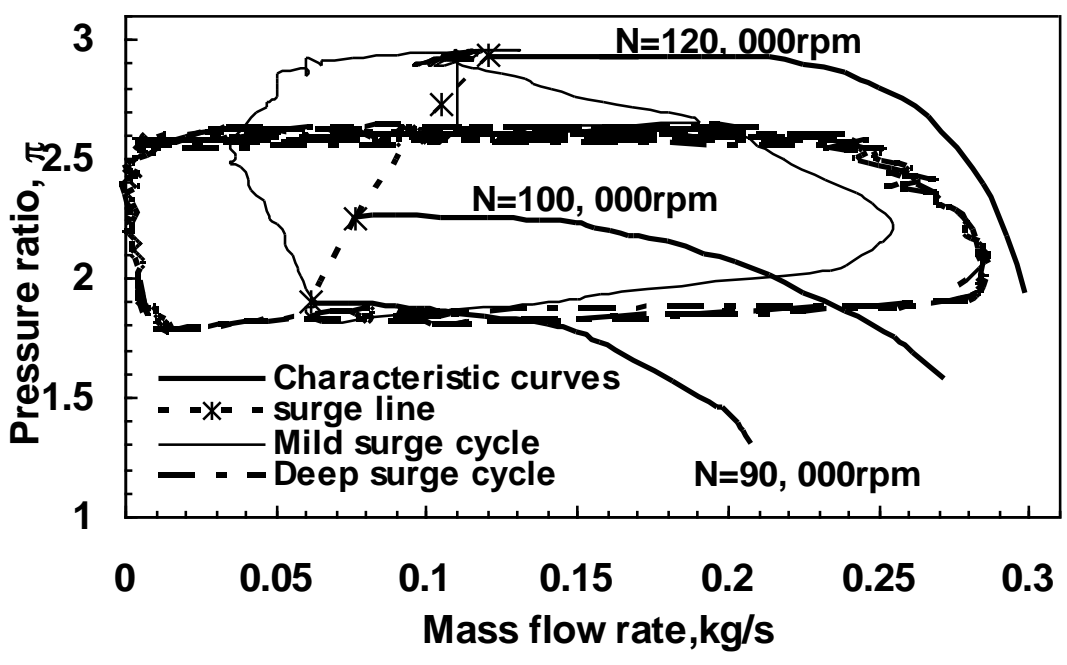

Fig. 9 Effect of intake manifold volume on compressor surge cycle

\subsection{Control of Compressor surge with Change of Throttle Valve Gain}

It must be mentioned here that, there have been many researches [example, 2531] were carried out to solve or control the surge problem, which limits the industrial turbomachinery performance. Few investigations [32-36] were made on surge control for the turbocharger of vehicle engine. The surge problem in a vehicle engine occurs mainly, when the throttle is closed very fast. Typically when the driver takes his/her foot off the gas pedal during gearshift, the requested air mass to the cylinders will be heavily reduced causing the control system to close the throttle [33]. However, references [32 and 33] show that the throttle valve in the turbocharger compressor with the diesel engine is the main cause for surge trigger. Therefore, it is important to correct the throttle characteristic to work as a throttle controller for surge. However, 
when modeling the throttle air mass flow rate $\dot{m}_{\text {air }}$, it is best to consider the air mass flow through a venturi, which is given by:

$$
\dot{m}_{a}\left(\alpha, p_{T i}, p_{T e}, T_{T i}\right)=p_{T i}[Q(\alpha) \Psi(\Pi)] / \sqrt{R T_{T i}}
$$

where the subscripts $T i$ and $T e$ are the conditions at throttle inlet and exit, respectively, $Q$ is a function depends on the opening area, $A_{T}$, and a discharge coefficient, $C_{d}$, that depends on the shape of the flow area; $Q_{t h}=C_{d} A_{T}$. However, a simple model for the throttle opening area can be written as:

$$
A_{T}=A_{o}+A_{1}\left[1-\cos \left(a_{o} \alpha+a_{1}\right)\right]
$$

where, $A_{O}$ is the leak presented area even though the throttle is closed, $A_{1}$ is the area that is covered by the throttle when it is opened and $\alpha$ is the throttle angle. The parameters $a_{o}$ and $a_{1}$ are constants. The discharge coefficient, $C_{d}$ is assumed to be constant, thus

$$
Q_{t h}=Q_{o}+Q_{1}\left(1-\cos \left(a_{o} \alpha+a_{1}\right)\right)
$$

The mass flow through the throttle $\left(\dot{m}_{T}\right)$ is modeled as:

$$
\dot{m}_{T}=K_{T}\left(p_{p}-p_{a}\right)^{0.5}
$$

where, $K_{T}$ is the throttle coefficient or gain proportional to throttle opening which will used as a controller. Equation (34) can be written in a nondimensional form as:

$$
\Phi_{T}=K_{T} \Psi_{p}^{0.5}
$$

On the other hand, different forms for the throttle gain as a controller were summarized in [34] and the throttle was modeled as follows:

$$
\Phi_{T}=\left(K_{T} \Psi_{p}\right)^{0.5}-0.1
$$

However, in the present study, large number of iterations was carried out to correct the throttle gain as a controller and a suitable form could be written as:

$$
K_{T}=(\Phi+0.1)^{2} /\left(H+1-1.5 \Phi+2.5 \Phi^{3}\right)
$$

Substituting Eq. (37) into Eq. (36), the flow coefficient through the throttle becomes:

$$
\Phi_{T}=\left[\Psi_{p}(\Phi+0.1)^{2} /\left(H+1-1.5 \Phi+2.5 \Phi^{3}\right)\right]^{0.5}-0.1
$$

Substituting Eq. (38) into Eq. (28) gives:

$$
\begin{aligned}
d \Psi_{p} / d \tau= & \left\{\Phi_{c}-\left[\Psi_{p}(\Phi+0.1)^{2} /\left(H+1-1.5 \Phi+2.5 \Phi^{3}\right)\right]^{0.5}-0.1\right\} / B \\
& -2 F B \Psi_{p} \Gamma
\end{aligned}
$$

Again, Eqs. (27), (28) and (39) were solved using the Matlab for $B, \Phi_{c}$ and $\Psi_{p}$ in Eq.(30) with $\Psi_{p}\left(\Phi_{c}\right)$ and $\Gamma\left(\Phi_{c}\right)$ as the specified compressor pressure and torque characteristic, respectively. The results show that with using the new gain of the throttle valve the surge was detected at flow coefficient of 0.065 while it was occurred at flow coefficient of 0.225 with the original compressor without controller [27]. That is, this controller increases the compressor range of stability about $33 \%$ and pressure 
coefficient about $15.4 \%$. It must be mentioned here that, although, the present paper corrected the throttle gain best than that used in [37] but it is clearly observed that, the throttle gain has more effect on improvement in the range of stable flow operation in the axial flow compressors than in the centrifugal compressors. This may be due to the effect of centrifugal action on the flow direction and the jump in the centrifugal compressor characteristic curve at surge condition is very severe with the centrifugal compressors than that with the axial compressors.

\subsection{Control of Compressor surge by Using Closed-Coupled Valve}

This part of the present work investigates effect of closed coupled valve (sensor and actuator) to control compressor surge to increase the engine range of stable operation. To do this, some assumptions were considered, similar to Nelson et al. [35] the total pressure at the compressor inlet is considered as a sensor and the valve that modulates the compressor exit area as actuator. This actuator is denoted as closecoupled valve as shown in Fig.10.

On the other hand, since the instantaneous flow through the compressor is the same as the flow through the close-coupled valve, by introduction of the control term $\Psi_{c c}\left(\Phi, \alpha_{c c}\right)$ which represents the nondimensional form of the pressure drop through the close-coupled valve $\left(\Psi_{c c}\right)$ as a function of flow coefficient $\Phi$ and the valve fraction open $\alpha_{c c}$, Eq.(27) becomes:

$$
d \Phi_{c} / d \tau=B\left(\Psi_{c}\left(\Phi_{c}\right)-\Psi_{p}-\Psi_{c c}\left(\Phi, \alpha_{c c}\right)\right)-F B \Phi_{c} \Gamma
$$

The total pressure at the compressor exit $\Psi_{O C}$ as a function of the variables $\Phi, \Psi$ and the input variable $\alpha_{c c}$ can be written as:

$$
\Psi_{o c}=\Psi_{c c}\left(\Phi, \alpha_{c c}\right)-\Psi_{c}(\Phi)+\Psi_{p}
$$

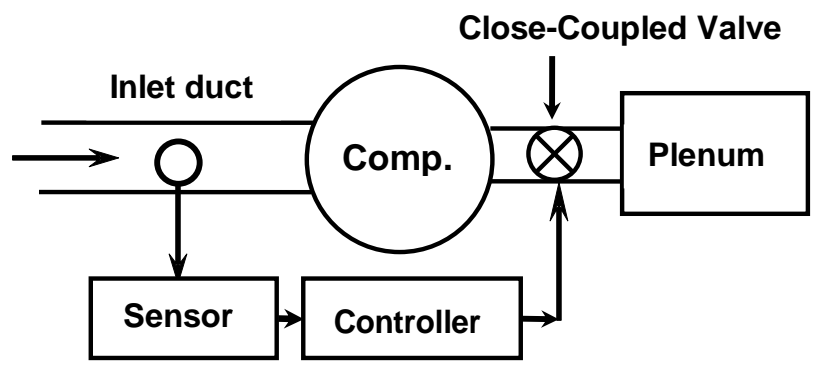

Fig. 10 Closed coupled valve control system

Effect of the sensor actuator on the compression system performance could be detected from its transfer function, $W(s)$, i.e., the ratio of the Laplace transformed system output (sensor signal $\Psi_{o c}$ ) to input (actuator motion $\alpha_{c c}$ ) which can be written as: 


$$
W(s)=\frac{\Psi_{o c}^{2}(s)}{\tilde{\alpha}_{o c}(s)}=\left[C_{c} B K\left(s+\frac{1}{B C_{T}}\right)\right] /\left[s^{2}+\left(\frac{1}{B C_{T}}-B C_{c}\right) s+\left(1-\frac{C_{c}}{C_{T}}\right)\right]
$$

where $\mathrm{s}$ is the Laplace transform variable, $C_{C}$ is the equivalent compressor slope for the combined valve and compressor, $C_{c}=\partial\left(\Psi_{c}-\Psi_{c c}\right), C_{T}$ is the slope of the throttle pressure drop versus flow characteristic, $C_{T}=1 /\left(\partial \Phi_{T} / \partial \Psi\right)$ and $K$ is the changes in the valve area to the valve pressure drop, $K=-\partial \Psi_{c c} / \partial \alpha_{c c}$. The system stability can be determined from the roots of the closed loop characteristic equation:

$$
W_{x 1}(s)+E W_{x 2}(s)=0
$$

where, $W_{x 1}(s)$ and $W_{x 2}(s)$ are the denominator and numerator polynomials respectively and $E$ is the real constant of proportionality in the control law. However, the compressor will run stably when the roots of Eq.(43) are negative real parts, while, when the control is off $(E=0)$, the compressor instability or surge point can be determined from the roots of $W_{x 1}(s)$ only. Whereas, at $E$ greater than zero, the compression system stability becomes strongly modified by the term, $E W_{x 2}(s)$. On the other hand, the compression system transfer functions defined as: the compressor mass flow is $B E\left(s+1 / B C_{T}\right) / D(s)$, the plenum pressure is $E / D(s)$, the compressor exit static and total pressures respectively are $-E s\left(s+1 / B C_{T}\right) / D(s)$ and $-E\left[s^{2}+\left(2 \Phi B+1 / B C_{T}\right) s+2 \Phi / C_{T}\right] / D(s)$.

Where, $D(s)=s^{2}+\left(1 / B C_{T}-B C_{c}\right) s+\left(1-C_{c} / C_{T}\right)$. Substituting these transfer functions into Eq.(43) and rearranging the results in a characteristic equation as follows:

$$
s^{2}+\left(1 / B C_{T}-B C_{c}+K B E\right) s+\left(1-C_{c} / C_{T}+K E / C_{T}\right)=0
$$

Equation (44) shows that, the compression system stability requires:

$$
\begin{aligned}
& \left(1 / B C_{T}-B C_{c}+K B E\right)>0 \\
& \left(1-C_{c} / C_{T}+K E / C_{T}\right)>0
\end{aligned}
$$

Examination of Eqs.(45-a and 45-b) shows that, all the parameters are positive numbers except for the compressor slope, $C_{c}$. However, operating the compressor at high flow rates i.e., when the compressor slope, $C_{c}<0$, the system will be stable with no feedback ( $K=0)$. When the engine runs at low flow rates, the compressor slope $C_{c}$ becomes negative, which reaches zero at the peak of the compressor characteristic curve, and then moves to the large positive value. That is, the system will be unstable without feedback. For sufficiently large values of the throttle gain $K$, all the parameters in Eq.(45) can be simultaneously satisfied and the system should be stabilized. However the compression system using controller of the closed coupled valve the surge was detected at flow coefficient of 0.13 in comparison of the compressor without controller. This improved the compressor range of stable operation about $20 \%$. 


\subsection{Control of Compressor surge with Auxiliary Plenum}

Ffowcs Williams and Hung 1989 [36] used a movable plenum wall, driven by a signal proportional to the unsteady plenum pressure, to suppress surge in a centrifugal turbocharger. The basic prediction is that a properly designed moving plenum wall can substantially increase the stable flow range of a centrifugal compressor system. Similar to Hassan [37], which use spring and damper with read valve in parallel to control the axial flow compressor surge, while the present work uses two damper and spring to suppress the surge in axial flow compressor. A schematic diagram of the compression system with auxiliary plenum is shown in Fig.11.

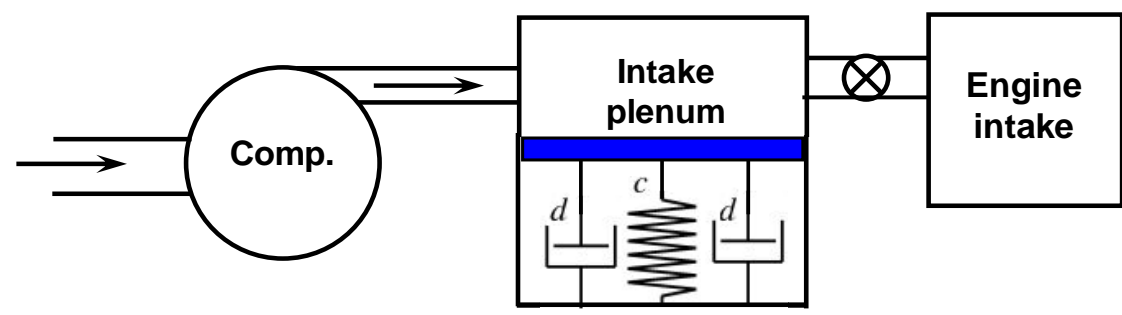

Fig. 11 Compression system with auxiliary plenum

Movable wall balancing equation can be written as:

$$
m \ddot{y}+d \dot{y}+c y=A_{p}\left(p_{p}-p_{p, a u x}\right)
$$

where, $y$ and $A_{p}$ are the plenum wall displacement and surface area respectively. The wall in the present work that has mass $m$ is a part of damper-spring-damper system responding to the unsteady plenum pressure perturbation, with a displacement $y$ that is proportional to the driving force. The change in plenum volume is $y A_{p}$ and the plenum mass change is $\rho y A_{p}$. Mass conservation equation in the plenum can be written as:

$$
\dot{m}_{T}-\dot{m}_{c}=V_{p} \frac{d p_{p}}{d t}+\rho_{p} A_{p} \frac{d y}{d t}=\frac{V_{p}}{a^{2}} \frac{d \Delta p_{p}}{d t}+\rho_{p} A_{p} \frac{d y}{d t}
$$

Using the nondimensional group: $\zeta=A_{p} y / V_{p}, M=u / a_{o}, \mathrm{Z}=\rho_{o} A_{P}^{2} L_{c} / m V_{p}$, $\xi=d / 2 m \sqrt{k / m}$. Then Eq. (43) with the movable plenum wall becomes:

$$
d \Psi_{p} / d \tau=\left(\Phi_{c}-\Phi_{T}\right) / B-2 F B \Psi_{p} \Gamma-\left(2 / M^{2}\right) d \zeta / d \tau
$$


The parameters $M$ and $\zeta$ are the wall displacement and tip Mach number in nondimensional form to measure the effect of wall motion on the mass balance in the plenum. B-parameter represents the magnitude of the positive compressor characteristic slope required for the disturbances to grow. The pressure drop through the throttle ( $\Delta p_{T}=0.5 \dot{m}_{T}^{2} / \rho_{T} A_{T}$ ) can be written in a dimensional form as:

$$
d \Psi_{T} / d \Phi_{T}=\Phi^{2} / 2 \Psi
$$

In addition, Eq. (46) can be written as:

$$
\frac{d^{2} \zeta}{d \tau^{2}}+2 \xi\left(\frac{\sqrt{k / m}}{\omega_{H}}\right) \frac{d \zeta}{d \tau}+\frac{k}{m \omega_{H}^{2}} \zeta=2 Z B^{2} \Psi
$$

To determine the effects of the auxiliary plenum on system stability or surge margin Eqs. (27, 48, 49 and 50) were written in a matrix form similar to [37] and solved using Matlab. The mean flow coefficient using the experimentally determined compressor characteristic curves of [27] enables prediction of the compressor instability onset condition for various system and control parameters. On the other hand, this matrix constitutes an eigen value problem for the complex growth rate, s, which can be obtained as a function of the parameters $B, M, \Psi, \Phi$. Therefore, the limit of stabilization for a given value of B-parameter, using this controller will occur at a point of the compressor characteristic where the slope $(d \Psi / d \Phi)$ is1/B. This slope can be compared with that of natural surge point, that occurs at a value of ( $d \Psi / d \Phi)$ given by substituting $d \Psi / d \Phi=\left(B^{2} \partial \Psi_{T} / \partial \Phi_{T}\right)^{-1}$. The results show that using the auxiliary plenum with the compression system as a dynamic control is effectively suppressed the centrifugal compressor surge and shift the surge line to the left about $25 \%$ in flow over a significant portion of the corrected speed range examined and increases the pressure coefficient at low flow rates about $10.8 \%$.

\subsection{Control of Compressor surge Using Bleed Valves}

In this part of the present work, effect of air bleeds between the compressor exit and inlet on the range of stable operation was investigated. A simple model includes the compressor inlet bleed through valves was represented. In this case, the mass flow bled by the valves $\Phi_{b}$ is an additional flow that appears in the balance $\Phi_{c}=\Phi_{d}+\Phi_{b}$ where $\Phi_{d}$ is the mass flow in the portion of the compressor downstream of the bleed valves. The pressure balance must include the pressure change $\Psi_{b}$ due to the bleed valves. The valves also influence the pressure change $\Psi_{d}$ across the downstream portion of the compressor and modify the pressure change $\Psi_{e}$ in the exit duct. Bernoulli's equation can be relating the upstream pressure $\Psi$, downstream pressure $\Psi_{d}$, and the bleed pressure $\Psi_{b}$ as: 


$$
\Psi+0.5 \Phi_{c}^{2}=\Psi_{d}+0.5 \Phi_{d}^{2}=\Psi_{b}+0.5 \Phi_{b}^{2}
$$

Using the valve pressure change as $\Psi_{v}=\Psi_{d}-\Psi$ and $\Phi=\Phi_{b}+0.5 \Phi_{d}$, then $\Phi_{d}$ can be eliminated to:

$$
\Psi_{v}=\Phi \Phi_{b}-0.5 \Phi_{b}^{2}
$$

The pressure change $\Psi_{d}$ across the downstream portion of the compressor stages is composed of two parts. The first part exists even when there is no bleed, while the second part is the pressure change introduced by the valves. Moore's model [37] gives the change of pressure across the downstream compressor portion as:

$$
\Psi_{d}=\alpha \Psi_{c}\left(\Phi_{d}\right)-\alpha(\lambda-\mu) \partial \Phi_{d} / \partial \theta
$$

where the constants $\lambda=1$ and $\mu=1.29$. In the present model $\Phi_{d}$ is replaced by $\Phi-\Phi_{b}$ and $\Psi_{c}\left(\Phi_{d}\right)$ is approximated by $\Psi_{c}\left(\Phi_{d}\right)=\Psi_{c}\left(\Phi-\Phi_{b}\right)=$ $\Psi_{c}(\Phi)-\Phi_{b} \partial \Psi_{c} / \partial \Phi$ and substitute in Equ.(53) to obtain

$$
\Psi_{d}=\alpha \Psi_{c}(\Phi)-\alpha(\lambda-\mu) \partial \Phi / \partial \theta-\alpha \Phi_{b} \partial \Psi_{c} / \partial \theta+\alpha \lambda \partial \Phi_{b} / \partial \theta+\alpha \mu \partial \Phi_{b} / \partial t
$$

Also, Moore's [37] gives the pressure changes $\Psi_{c}$ due to effect of the bleed valves as a function of the downstream mass flow $\Phi_{d}$, in terms of the upstream mass flow $\Phi$ and the bleed mass flow $\Phi_{b}$

$$
\begin{aligned}
\Psi_{e} & =-L_{c} \partial \Phi_{d} / \partial t-(m-1) \partial \delta \Phi_{d} / \partial t \\
& =-L_{c} \partial \Phi / \partial t-(m-1) \partial \delta \Phi / \partial t+L_{c} \partial \Phi_{b} / \partial t+(m-1) \partial \delta \Phi_{b} / \partial t
\end{aligned}
$$

Where $L_{c}$ is the compressor duct length. In Eq.(54), the mass flow is split into its mean $\bar{\Phi}$ and the deviation $\delta \Phi$ from the mean $\Phi=\bar{\Phi}+\delta \Phi$ :

The effect of bleed valves can be expressed by collecting Eq.(52), (54), and (55) as:

$$
\begin{aligned}
\Psi_{b}= & \Phi_{b}\left(\Phi-\alpha \partial \Psi_{c} / \partial \Phi-0.5 \Phi_{b}\right)+\alpha \lambda \partial \delta \Phi_{b} / \partial \theta \\
& +L_{c} \partial \Phi_{b} / \partial t+(\alpha \mu+m-1) \partial \delta \Phi_{b} / \partial t
\end{aligned}
$$

Effect of bleed on the compressor stability and performance can be detected by inserting Eq.(56) into Eq.(28) and solving Eqs. (27), (28) with (56) using the Matlab for $B, \Phi_{c}$ and $\Psi_{p}$ with $\Psi_{p}\left(\Phi_{c}\right)$ and $\Gamma\left(\Phi_{c}\right)$. The results show that the surge occurs at flow coefficient $\Phi=0.15$ and about $16 \%$ improvement in compressor range of stable operation was detected. Figure12 shows conclusions of the influence of different controllers on compressor range of stable operation. The mass flow coefficient at which surge occurs with the original compressor [27], is at flow coefficient of $\Phi=0.225$, while with optimum throttle valve gain the surge occurs at flow coefficient of 0.065 . 


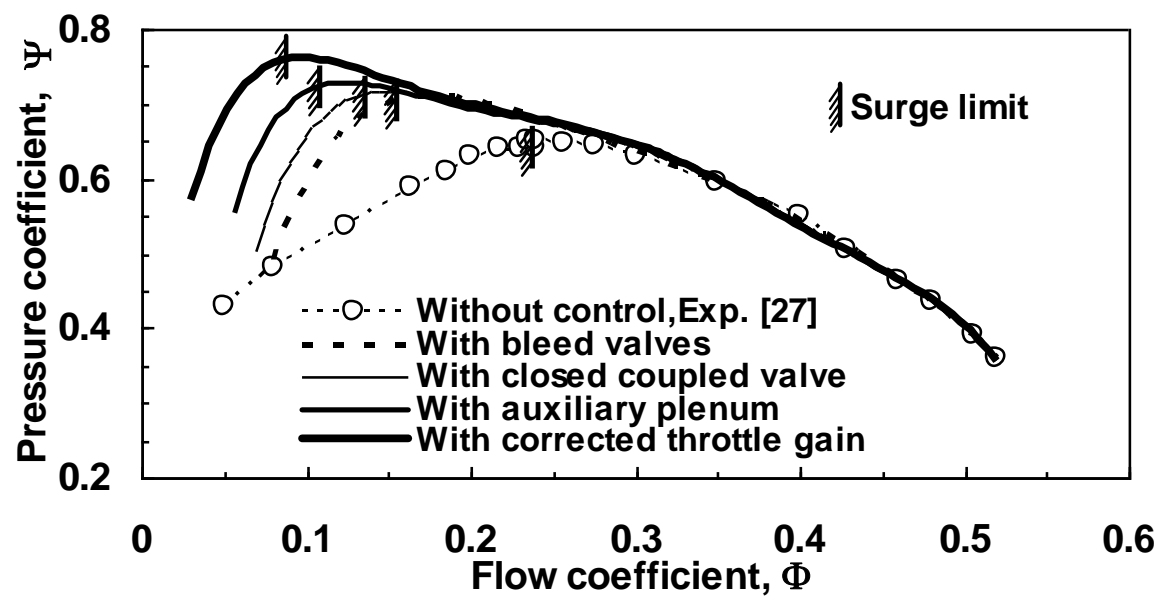

Fig. 12 Effect of controller on compressor range of stable operation

That is correcting the throttle valve gain improved the compressor range of stable operation about $33 \%$ and $15.4 \%$ in pressure coefficient. The auxiliary plenum gives about $25 \%$ enhancement in the stable flow range and $10.8 \%$ in compressor pressure coefficient. The close-coupled control valve increases the compressor stable flow range about $20 \%$, while, the bleed valves increases the compressor range of stable operation by about $16 \%$.

\section{CONCLUSIONS}

To avoid the turbocharged diesel engine from the very dangerous problem of compressor surge, different techniques for surge suppression and control were investigated. First, simple model for the turbocharger with the diesel engine was created, to investigate the effect of air filter, intake manifold, intercooler, exhaust manifold, exhaust system, exhaust gas recirculation, compressor and turbine on the engine performance. Effect of operating the compressor in surge condition on the engine performance was investigated. Different techniques to suppress or for control the surge phenomenon and increase of the range of stable operation of the compressor were carried out. These techniques are: changes of the engine intake manifold volume, optimum throttle valve gain, auxiliary plenum with damper-spring-damper system, close-coupled valve and bleed valves.

The results show that:

1. The engine volumetric efficiency and the output power were increased by increasing the intake pressure.

2. Increasing the residual gas fraction decreases the exhaust manifold temperature and the engine output power.

3. Decreasing the volume of engine intake manifold increases the compressor limit of stable operation and the engine stability.

4. Correcting the throttle valve gain improved the compressor range of stable operation by about 33 percent and the pressure coefficient by about $15.4 \%$. 
5. Using an auxiliary plenum with damper-spring-damper system shifted the surge point to the left about $25 \%$ of the compressor maximum flow rate and increases the pressure coefficient by about $10.8 \%$ at low flow rates.

6. The close-coupled valve as controller for compressor surge gave about $20 \%$ enhancement in the range of stable flow rate.

7. Using the bleed valves between the compressor up and downstream gives about $16 \%$ increase in range of stable operation.

8. Operating the compressor in surge condition leads to decrease the airflow to the engine, which causes incomplete combustion, and decrease of the engine output power.

9. Comparisons of the present results with the available previous experimental and theoretical data showed good agreements.

\section{REFERENCES}

1. Yokomuro, H., Kohketsu, S. and Mori, k., "EGR System in a Turbocharged and Intercooled Heavy-Duty Diesel Engine - Expansion of EGR Area with Venturi EGR System”, Engine Research Dept., Research \& Dev. Office, MFTBC-Japan, 2003.

2. Avinash, K. A., Shrawan, K. S., Shailendra, S. and Mritunjay, K. S., "Effect of EGR on the Exhaust Gas Temperature and Exhaust Opacity in Compression Ignition Engines", Kanpur 208 016, India, Sadhana, Vol.29, pp. 275-284, June 2004.

3. Eriksson, L., Nielsen, L., Brugard, J., Bergstrom, J., Pettersson, F. and Andersson, P., "Modeling of a Turbocharged SI Engine", Annual Reviews in Control 26, Elsevier, pp. 129-137, 2002

4. Brugard, J., Lars, E. and Lars N., "Mean Value Engine Modeling of a Turbocharged Spark Ignited Engine - a Principle Study", Tec. Report, Dept. of Elec. Eng., LiTH-ISY-R-2370, ISSN 1400-3902, 2001.

5. Holman, J. P., "Heat Transfer", Second edition, McGraw-Hill, 1997.

6 . Hendricks, E., "Isothermal vs. Adiabatic Mean Value SI Engine Models", In: $3^{\text {rd }}$ IFAC Workshop, Advances in Automotive Control, Preprints, Karlsruhe, Germany. pp. 373-378, 2001.

7. Vadim, I. U., Haochi, C. and Ilya, K., "Controlling Variable Geometry Turbocharged Diesel Engines Using Sliding Mode," the Ohio State University, Columbus, OH 43210, U.S.A, 2002.

8. Utkin, V., Chang, H., Kolmanovsky, I. and Cook, J. "Sliding Mode Control for Variable Geometry Turbocharged Diesel Engines," Proceedings of American Control Conference, 2000.

9. Mueller, V., Christmann, R., Muenz, S., and Gheorghiu, V., "System Structure and Controller Concept for an Advanced Turbocharger/EGR System for a Turbocharged Passenger Car Diesel Engine”, Borg Warner Turbo Systems, H, University of Applied Sciences, Hamburg, Germany, 2005. 
10. Kristoffersson, I., "Model Predictive Control of a Turbocharged Engine", Ms thesis, Performed at S3 for General Motors Power train, Stockholm, Sweden, 2006.

11. Filipi, Z., Wang, Y., and Assanis D., "Effect of Variable Geometry Turbine (VGT) on Diesel Engine and Vehicle System Transient Response", Automotive research center, University of Michigan, 2001.

12. Dambrosio, L., Pascazio, G. and Fortunato, B., "VGT Turbocharger Controlled by an Adaptive Technique", ASME Trans on Mechatronics, Vol. 8, December 2003.

13. Jung, M., Ford, R., Glover, K., Collings, N., Christen, U. and Watts, M., "Parameterization and Transient Validation of a Variable Geometry Turbocharger for Mean-Value Modeling at Low and Medium Speed-Load Points", University of Cambridge and Society of Automotive Engineers, Inc.01-2729, 2002.

14. Elfvik, D., "Modeling of a Diesel Engine with VGT for Control Design Simulations" M.Sc. thesis, Dept. of Signals, Sensors and Systems, Stockholm, Sweden, July 2002.

15. Guzzela, L. and Amstutz, A., "Control of Diesel Engines", IEEE Control Systems, AC-37(7):53.71, October 1998.

16. Stutte, T., Nyberg, M. and Wilhelmi, V., "Model Based Diagnosis of the Air Path of an Automotive Diesel Engine", In IFAC Workshop: Advances in Automotive Control, Karlsruhe, Germany, 2001.

17. Skogtjarn, P., "Modeling of the Exhaust Gas temperature for Diesel Engines", M.Sc. Thesis g Dept of Elec. Eng., Linkopings University, Sweden, December 2002.

18. Ritzier, J., "Modeling and Fixed Step Simulation of a Turbocharged Diesel Engine", Ms thesis, Dept. of Elec. Eng., Linkopings Un., LiTH-ISY-EX-3442, Sweden, 2003.

19. Agrawal, A., Singh, S., K. and Kumar, M. "Effect of EGR on the Exhaust Gas Temperature and Exhaust Opacity in Compression Ignition Engines", Dept. of Mech. Eng., Kanpur 208 016, India, Sadhana, Vol. 29, Part 3, pp. 275-284, June 2004.

20. Bergstrom, J. and Brugard, J., "Modeling of a Turbo Charged Spark Ignited Engine", Linkopings Institute of Technology, LiTH-ISY-EX-3442, Sweden, 1999.

21.Pettersson, F., "Simulation of a Turbocharged Spark Ignited Engine", M. Sc. Thesis, Linkopings university, LiTH-ISY-EX-3442, Sweden, 2000.

22. Watson, N., and Janota, M.S., "Turbocharging the Internal Combustion Engine", Macmillan Press, London, 1982.

23. Biaggini, G., Buzio, V., Ellensohn, R., and Knecht, W., "The New Iveco Cursor and Diesel Engine", MTZ Motor technique aircraft, 10-1999, pp. 640-649, 1999.

24. Klingmann, R., Fick, W., and Bruggemann H., "The new Common Rail Direct injection Diesel Engines for the updated E-class Part 2: Combustion and Engine Management”, MTZ Motor technique aircraft, 7/8-1999, pp. 426-437, 1999.

25. Greitzer, E.M., "Surge and Rotating Stall in Axial Flow Compressors", Part I:, ASME J. of Eng. for Power, 98, pp. 190-198, 1976. 
26. Skopil, M., and Bulaty, T., "Calculation of Compressor Surge with Unsteady Flow Model", IMechE International Conference on Turbocharging and Air Management Systems, C554/018/98, pp. 219-225, London, 1998.

27. Fink, D.A., Cumpsty, N.A., and Greitzer, E.M., "Surge Dynamics in a Free-Spool Centrifugal Compressor System", ASME J. of Turbo., 114, pp.321-332, 1992.

28. Chesse, P., Hetet, J., Tauzia, X., and Inozu, B., "Performance Simulation of Sequentially Turbocharged Marine Diesel Engines with Applications to Compressor Surge", Proc. ASME, Tec. Conf., Vol. 30-2, pp. 31-40, Florida, April 26-29, 1998.

29.Moore, F. K., and Greitzer, E.M., "A Theory of Post-stall Transients in Axial Compression Systems. Part I: Development of Equations", ASME J. of Eng. for Gas Turbines and Power, 108, pp. 68-76, 1986.

30.Japikse, D., and Baines, N.C., "Introduction to Turbomachinery", Concepts ETI Inc., Norwich, 1994.

31. Guzzella, L. and Amstutz, A., "Control of Diesel Engines", IEEE Control Systems Magazine, Vol. 18, No. 5, pp. 53-71, 1998.

32.Gravdahl, J.T., "Modeling and Control of Surge and Rotating Stall in Compressors", Report 98-6-W, Norwegian University of Science and Technology, 1998.

33.Wiklund, E., and Forssman, C., "Bypass Valve Modeling and Surge Control for Turbocharged SI Engines", M.Sc., Reg. Thesis, LiTH-ISY-EX-3712, Sweden, 2005.

34.Gupta, R. and Ananthkrishanan, N., "Survey of stall/surge Dynamics and control Techniques in Axial Flow Compressors", J. of Aeronautical Society of India, 1999.

35.Nelson, E., Paduano, J. and Epstein, A., "Active Stabilization of Surge in an Axial Centrifugal Turboshaft Engine", ASME J. of Turbomachinery, Vol. 122, pp. 485493, 2000.

36. Ffowcs, F.E., and Huang, X.Y., "Active Stabilization of Compressor Surge", ASME, J. of Fluid Mech., Vol. 204, pp.245-262, 1989.

37. Hassan, A. S., "Active Suppression of Aerodynamic Instabilities in the Axial Flow Compressors", Journal of Eng. Sciences, Faculty of Eng. Assiut University, Vol. 29, No.2, pp. Nov. 2006.

38. Moore, F. K., "A theory of rotating stall of multistage axial compressors: part Ismall disturbances," J. Eng. Gas Turbines Power, vol. 106, pp. 313-320, Apr. 1984.

\section{نمذجة شاحن توربينى لمحرّكِ ديزل والتحكم فى مدى غطغطة الضاغط}

إنّ الهدفَ الرئيسيَ من هذا البحث هو حماية محركَ الديزل ذو المحرّك النفّاثَ منْ مشكلةِ غطغطة الضاغطات الخطرة جداً على المحرك ـ ولذلك تم بحث أضافة أجهزة سبطرة مختلفة

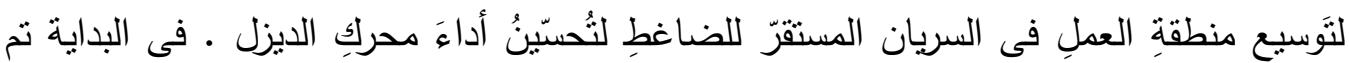


عمل نموذج بسيط للثاحنِ التوربينى بمحركِ الديزل لدراسة تأثيرِ كلا من: مرشّح الهواء، أنبوب

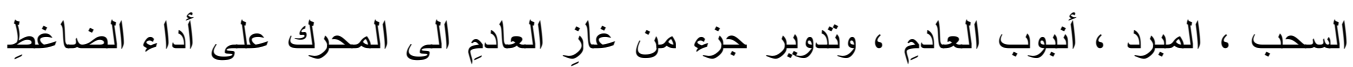

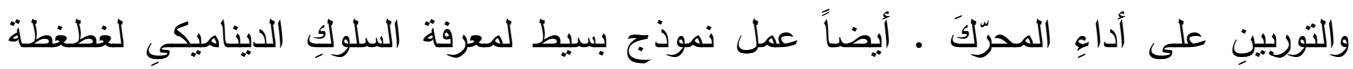

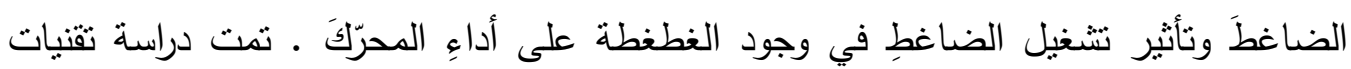

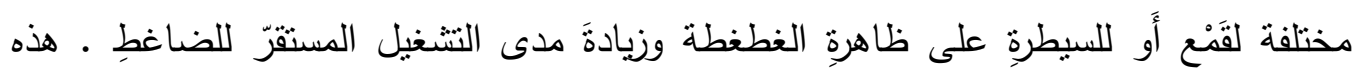
التقنياتِ كَانتْ: تغيير حجمِ ماسورة مدخل المحرك ، وتحسينِ مكافى الصمام الخانقَ، أضافة خزان مساعد مزاوج بمسبط وسوستة ومسبط لاخماد الغطغطة ، و تأثثر الصمامِ المُزَاوَجِ المُغلقِ ،



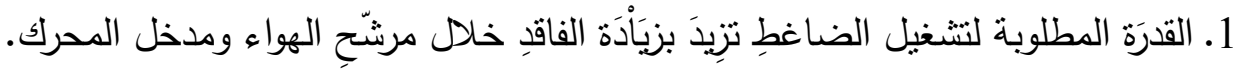

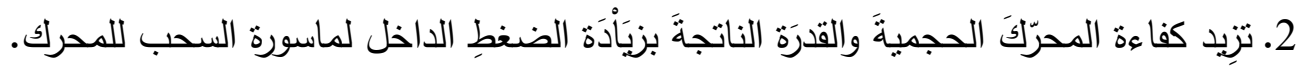

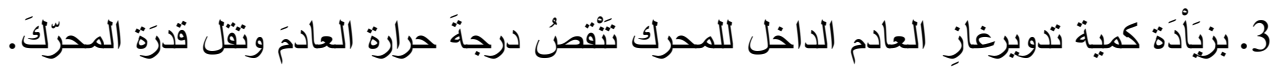

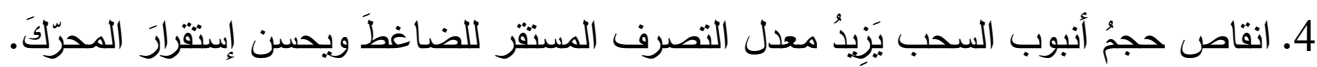

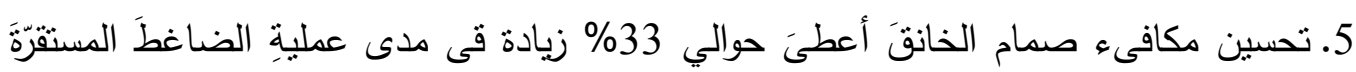
وكذلك الضغط المكافى بحوالى 15.4\%

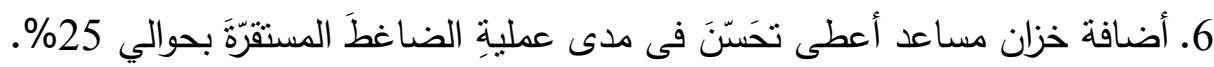

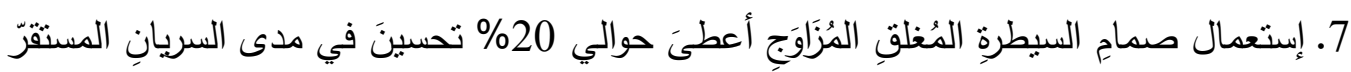
للضاغطِ .اما صمامات النزفِ فاعطت حوالى 16\% تحسينَ في مدى السريانِ المستقرّ للضاغط . للفاع.

8. عمل مقارنات للنتائجِ الحاليةِ بالبياناتِ التجريبيةِ والنظريةِ السابقةِ أظهرت تطابق معقول. 